\title{
Revelation and Reflection on Mankind by Modern Physics-Part II: Consideration on Multidimensional Universe
}

\author{
Samo Liu \\ University Science and Technology Beijing, Beijing, China \\ Email: samo945@126.com
}

How to cite this paper: Liu, S. M. (2019). Revelation and Reflection on Mankind by Modern Physics-Part II: Consideration on Multidimensional Universe. Open Journal of Philosophy, 9, 72-81.

https://doi.org/10.4236/ojpp.2019.92007

Received: April 7, 2019

Accepted: May 2, 2019

Published: May 5, 2019

Copyright $\odot 2019$ by author(s) and Scientific Research Publishing Inc. This work is licensed under the Creative Commons Attribution International License (CC BY 4.0).

http://creativecommons.org/licenses/by/4.0/

\begin{abstract}
This paper explores the multi-dimensional universe and raises questions on intelligent matters. It also explores the possibility of material transfers between the three-dimensional universe and higher dimensional universe. The author proposes that the origin of the universe is energy and that the existence of the three-dimensional universe based on matters is a special form of existence in the multi-dimensional universe. The paper also comes with the concept of intelligent matters for which the humankind is part of.
\end{abstract}

\section{Keywords}

Multidimensional Universe View, Intellectual Matter View, Intelligence, Pondering, Exploring the Universe

\section{Thoughts of the Universe from Mankind}

\subsection{Questions}

Being a type of intellectual matter, human, on the one hand, is insignificant in regard of materiality. In the endless universe, human seems negligible for its materiality. Both human's existence and extinction are ephemeral from the perspective of infinite time. On the other hand, human is significant because of its intelligence which allows human to think, summarize, act and cooperate. Thought and action promote human to develop from forest to villages, and from cities to counties with its vision that has been extended from forest to the universe.

Modern physics and modern cosmology have brought the vision and wisdom of humankind from the three-dimensional universe to the four-dimensional universe (Chechin, 2010; Godlowski, 2011). Theories such as the theory of relativity, quantum mechanics, the theory of Big Bang, or theory of black holes have 
brought our mind into the multi-dimensional universe (Chechin, 2012). To an extent, they confirmed the ideologies proposed by sages from the classic period millennia ago (Su \& Chu, 2009). A great revolution in philosophy and physics might already be in the horizon (Berman \& da Costa, 2012). Therefore, "modern" tells us that the universe consists of $4.9 \%$ of matter and $95.1 \%$ of dark matter and dark energy (Sebastian, 2014). Figure 1 shows the simulated diagram of the earth and even solar system observed from distance more than 10,000 light years $(100,000$ trillion $\mathrm{km})$. The earth could not be found in the figure and let alone the human. The galaxies and star maps are supposed to be optical image existed years ago. Are they still there now?

According to Dirac's theory, the particle characterized with wave-particle duality exists and doesn't exist at the same time. But it does in fact exist in the three-dimension, because things we see are composed of particles, as showed in Figure 2.

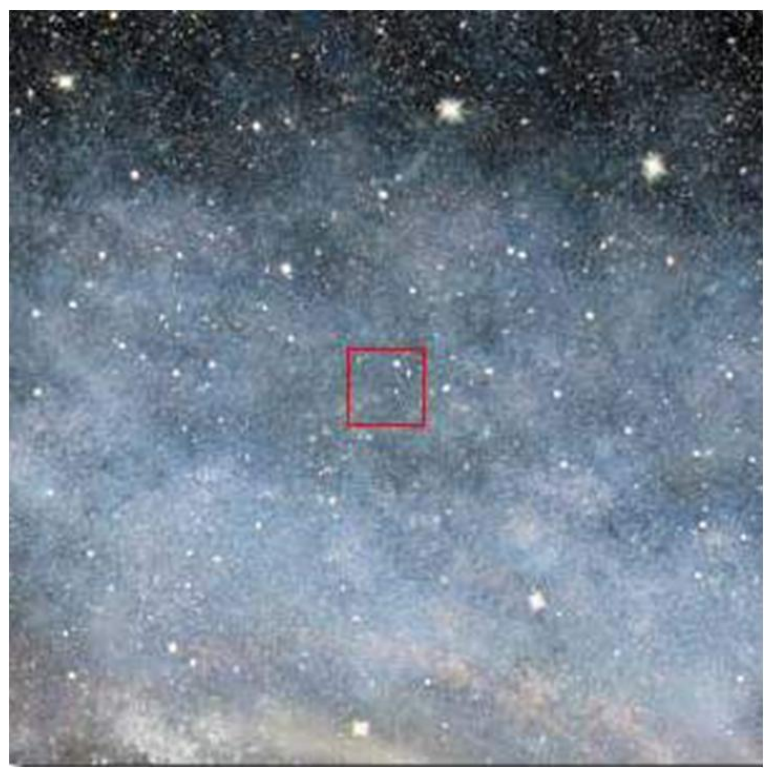

Figure 1. Observing the earth from 10,000 light years away (100,000 trillion km).

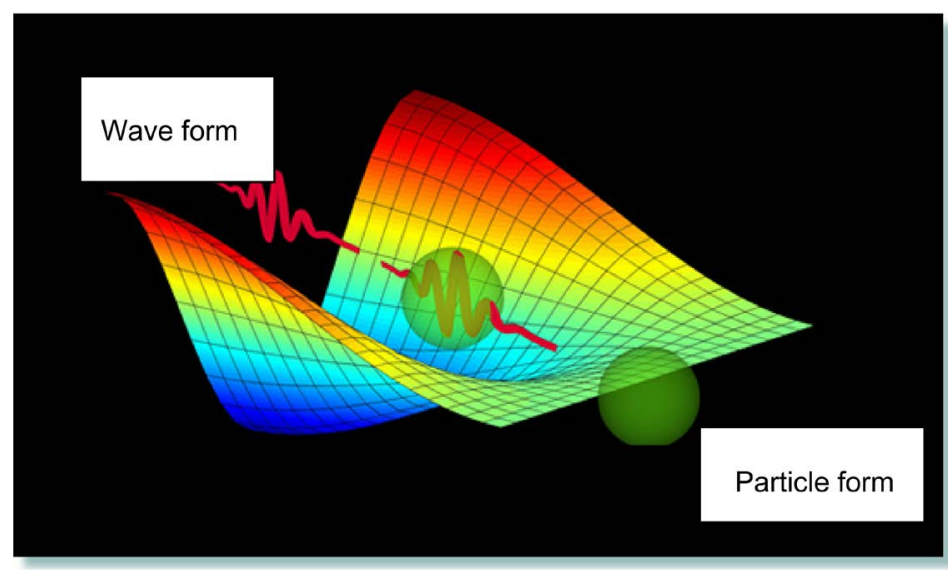

Figure 2. Diagrammatic drawing of quantum characterized with wave-particle duality. 
The questions mentioned above are indicated in both modern physicals and cosmology, which also needed to be paid special attention, too. These questions suggest that to live better, human is supposed to learn from the past, live in the moment and explore the universe. We'd better think in the perspective of the universe and quantum.

\subsection{Thought from Physics}

Physics is the method and tool for human to wisely think, act, explore, and discover the universe and the world, then to rethink and re-act to improve living and development.

Facing to the universe and space-time, mankind is in the process to learn and discover them, and contribute and create nearly nothing for it but keep demanding. It should be appreciated that in the process of learning, we invented objects that benefit for human's living and development according to the universal rules $(\mathrm{Ni}, 2008)$. However, all these inventions are derived from human's intelligent, thinking and action.

\subsection{Philosophic Thought}

Philosophy may have multiple concepts and definitions. The author believes that in the essence, it is one of the most significant characteristics of human: knowledge of thinking, which is the goal of human's actions (Liu, 2017). Ancient Greek philosophy is a spectrum of knowledge including various disciplines. To make philosophy more refined, Aristotle developed it into an independent discipline. It is said that philosophy is the science for the science, and it is supposed to cover everything. Specifically speaking, philosophy is the intelligence study and methodology for the daily life and work; it is supposed to summarize the past, guide the present and hypothesize the future. The hypotheses for the future may be wrong, but the closer the thoughts and hypotheses to the fact, the more functional they are to the action. Its correctness needs scientific test and experiment.

Therefore, religion is philosophy, so is physics.

Someone contended that "philosophy has died." The truth is not supposed to be like that. As long as humans exist, the unknown remains, and thinking continues, the science shall not stop and philosophy shall never die.

Ancient human was one species of animals living on the earth. The primitive subsistence referred to looking for food via their primitive intelligence. And it was the intelligence that made human stand out of other animals and then created civilizations. However, since the establishment of civilization, human's history has been dominated by their desires, including the mental desires and material desires. So, it should be admitted that desires are the base for human's survival. Human should also think how to live better and longer. Desires also have been defined as root of evils in all kinds of religions. This definition is not groundless, on the contrary, it is based on ancient religion sages' understanding 
about the universal truth. Perhaps if human want to a long-term survival, it is essential to overcome or control or eliminate their desires.

It is obviously impossible to terminate human's desire at present, but it is still available to take in under control.

In the process of summarizing past, what philosophy could take away from such endeavor remains unknown.

\section{Metaphysical Introspection}

\subsection{Introspection on History}

In the history, the objective threats to human's survival were diseases and hunger. Nowadays, as science develops, threats to human existence have been gradually controlled and overcome, though they have not been extinguished entirely. For these two aspects, human should have a globally agreed thought and action to live better and longer. Science and introspection shall be priorities.

\subsection{Introspection on Wars}

The third factor threatening human's living and development is wars. The root for wars, from the perspective of matter, is desires; and from the perspective of spirit, it is the cultural and ideological divergence. Therefore, the sources of wars are related to philosophy and thoughts. How to guide human's behavior with thinking is expected to be a philosophic introspection.

In the aspect of thinking, we should focus on how to live peacefully among different individuals, counties, and classes and how to live harmoniously with the universe.

\subsection{Introspection on Cosmology Outlook}

Our ancestors have learned certain knowledge about the universe. With the advancement of science and technology, we both affirm and negate some points of the knowledge. But how much do we really understand about it? Do we truly comprehend ancestors' thinking and feeling then? Modern physics keeps developing. Considering that science is an endless project needing to be explored, philosophy and thinking should keep pace with it. As human's living desire expands, our cosmographic sense keeps reducing.

Facing the endless universe and three-dimension space-time, we are expected to further understand ancestor's philosophy, keep question about universe, guide mankind to live peacefully and unitedly, and integrate our thoughts with cosmographic wisdom.

\section{Multidimensional Universe Outlook}

\subsection{Mass-Energy Conversion between Three-Dimension and Four-Dimension}

Universal space-time is an objective reality. The essential form of the objective multi-dimensional existence is energy. The energy form varies as the dimensions 
change.

Three-dimension space is a special space for the universe existence. The form for the energy existence is matter which is touchable and visible. Its existing rule follows the classic physics based on Newton's mechanics principles. Most of the results achieved in the modern life originate from that.

Four-dimension space is supposed to be the space for energy conversion, which is impalpable and invisible. In this space, energy could be conversed to the matter of three-dimension space in the condition of the ultimate physical parameters; and vice versa. To be exact, four-dimension is not a space (temporarily described as space), or it could be defined as "quantum vacuum" in the aspect of quantum mechanics. It follows the Theory of Relativity, and some of the scientific laws revealed by quantum mechanics and modern cosmology remain further discussion and improvement. For example, the known four-dimension space parameters include wave, field, light, light velocity, density limits of matter, temperature limit, etc.

The principles for the mass-energy conversion and energy conservation between four-dimension space and three-dimension space follow the rules described in the Book of Change: yin contains yang; yang contains yin, and they are in interconversion, following the conservation of energy.

The dark matter and dark energy existing in the universe are supposed to be the energy in the four-dimension space, and so are the wave and field. From microcosmic perspective and rules from quantum mechanics, "quantum vacuum" should be four-dimension space. Rules of four-dimension space are expected to include those in three-dimension space. The classic physics works perfectly in three-dimension space. Modern physics develops based on the classic physics, and the latter is the base for the three-dimension space and the former is the base for four-dimension space.

Great physicists and scientists are also great philosophers, who open the gate of four-dimension space and expand human's horizon to the universe. Composed of matter and intelligence, three-dimension world should be the most wonderful one. Four-dimension space or above are complicated. Matter is touchable and visible in three-dimension space, so it is convenient to be explored. On the contrary, matter in four-dimension space or above is impalpable and invisible, thus difficult to explore. Since human is intelligent and wise, the problems will be solved. It can be ensured that the breakthrough made in four-dimension space will bring tremendous progress for human being.

Thousands of years ago, ancient sages already had the conception about four-dimension space and multi-dimension space (Jiang, 2001). They perceived it in an extremely quite environment with their wisdom and love to mankind during their practices. Limited to the words available in modern time, they could only have described the universe and space with "kong", "dao", "qi", "yitai", "yi" and other ancient words (Chi, 1985).

For thousands of years, we have been paraphrasing ancestors' thought in a laical way, and therefore created numerous mythologies (Rahula, 1974). It is true 
that some myths are incomplete records of history, like wars and flood. But some of them are mythicized social states, like the Jade Emperor (the supreme deity of Taoism) (Peterson, 2016).

Modern physics has verified that oriental religions have been practicing for thousands of years. Ancient sages discovered truth about the universe when they were practicing in a specific situation. Sages include the Yellow Emperor, Fuxi, Laozi and Sakyammuni in the East, and Thales, Pythagoras, Parmenides and Socrates in the West (Laotse, 2012; Le Guin, 1968, 1970, 1990, 1998). They educated people how to live; they described the conversions between four-dimension and three-dimension space; and they even sensed five-dimension. Five-dimension might be an intelligence space, which could only be defined when four-dimension laws are improved.

\subsection{Parameters for Four-Dimension Space}

The four parameters of matter are time, size, density and temperature.

\subsubsection{Time}

Einstein discovered the relation between time, light, and speed, and thus discovered the four-dimension space.

As long as three-dimension matter exists, its time measurement, such as moving speed and light, exits. The speed limit of three-dimension is light speed, and the time limits are zero.

Four-dimension is "Kong", which means no words can describe its status and objective existence, and so does its time. Light and time are the boundary between four-dimension and three-dimension.

\subsubsection{Size of Matter}

Tangible matter has no maximum size. No matter how large a piece of matter is, like a planet or galaxy, it is in the universe. The "space" in the three-dimension is the mother of all things in the universe. However, this space (including all things) contains four-dimension and orients from four-dimension.

At the same time, matter has no minimum size butter a smaller size. The smallest particle appears in quantum field. The limit of particle is wave, which means it is a part of the four-dimension. The dimorphism of wave and particle has conditions, and it is sure that scientists will give it a proper conclusion. Therefore, particle is the boundary of four-dimension and three-dimension.

Quantum mechanics, modern cosmology, and the theory of relativity have found the interconversion rules between four-dimension and three-dimension from microcosmic perspective and macroscopic perspective separately. For instance, Quantum Entanglement Theory may be the theory for the boundary of the two dimensions. Once breakthrough was achieved of this boundary theory, it would be the significant contribution to the science.

\subsubsection{Density}

All matters have density. The density of infinitesimal matter tends to be zero and 
"Kong" which refers to four-dimension. The density of infinite matter will be black hole at the extremity. It will become the energy in the four-dimension. Black hole theory, at this degree, really makes sense. Therefore, black hole may be the boundary between four-dimension and three-dimension.

\subsubsection{Temperature}

Temperature is an important parameter for matter's existence. The infinitely high temperature will become light and other energy form of four-dimension. And the infinitely low temperature will be zero. And matter's form will change tremendously with the temperature, remaining as energy.

\section{Intelligent Matter Outlook}

\subsection{Intelligent Matter}

There are all sorts of matter in the three-dimension world, and each of them possesses a special internal space connecting to the multi-dimension spaces. There is one matter in the East having a unique internal space, which is called "Jingluo (main and collateral channels in the human body)" or "acupuncture point". This space, at certain conditions, could connect to multi-dimension spaces. This kind of matter is called intelligent matter and human is called human being.

Ancient human has been suffering numerous tribulations for long time in the history and became what we are nowadays. In the infinite three-dimension universe, human is one of the intelligent matters, therefore there is undoubtedly other intelligent matters, like extraterrestrials.

Compared with the human lifetime, each second is just a moment; compared with human's history, human lifetime is just a moment; compared with universal history, human's existence is also just a moment. Instead of worrying about the theory of threats to human existence, we'd better pay attention to analyze and explore the potential threat factors to human's survival and their solutions.

Human has overcome most of existing threats via its powerful life force. Up to now, most of people live well while some of them still struggle in poverty and wars. The war threats on the earth haven't been terminated, but the universal threats still exist. Therefore, it is a significant question needed to be considered that how to live longer and better.

Human is supposed to explore and think about the universe with their infinite wisdom and intelligence.

\subsection{Intelligent Energy}

Multi-dimension (may be above five-dimension) is special energy, which is called intelligent energy. It is pure energy and usually doesn't combine with matter in the universe. Only when it naturally and harmoniously combines with specific matter can it show the intelligence of the matter and characteristics of intelligent matter. 
Like other matter in three-dimension, the intelligent matter generates naturally in the spacetime, but it is extremely rare. It is sure that human is not the only intelligent matter. Though specific existence form and thinking condition of other intelligent matter are unknown, one thing is ensured: that if intelligent matter exists in the universe, there must be its impetus and energy. The common characteristics shared by intelligent matter are that they are intelligent, and that they can think and act; they are the natural combination of intelligent matter in three-dimension and intelligent energy in multi-dimension.

Any matter from four-dimension space will return to the space. Since energy remains, in certain conditions it will return to three-dimension and keeps that circulating.

Intelligent matter should think about how to get out of the circulation. There might be other intelligent matter in the universe possessing the ability to solve the problem, and being immortal, but we human still haven't find the answer, because we focus most of our attention on the internal fights and arguments, remains in solving the internal existence problems, and has no ability to solve the threats from out space.

\section{Thinking about the Future}

At present, there are still some people living in poverty. The developed countries and the wealthy are considering about how to pull those people out of the current situation. If there are still people dying from starvation. It should be the shame for all humanity. The threats from diseases reduced. The further improvement of science and medicine will help human live better and longer. China's "One Belt One Road Initiative" will contribute the peaceful development of the world. Now the threats of wars still exist. We need to analyze reasons for wars and end them with wisdom, for instance:

For the people fighting for resources and land: guide them to explore the universe. There are unlimited land, resources and space. Stop being confined to the earth.

For the people fighting for beliefs: all the beliefs established by ancient sages are in common which aim at people's better lives. All the wars caused by different beliefs are blasphemy to the beliefs themselves.

The extraterrestrials are also intelligent matter. As human being, we need learn how to live peacefully first, then learn how to live with the extraterrestrials. They may primitive people, or have strange appearances, or have the thinking modes and cultures that we can't understand; or they may have extremely advanced science and even the ability close to gods. No matter how they are, the wisdom left by our sages might be the way to deal with the extraterrestrials.

There are lots of threats from universe. Once it happened, it would be catastrophic to the earth. The cosmology tells us that sun and other planets compose the solar system; as a part of the galaxy, it keeps an endless move at a high speed in a certain orbit. Considering the environment for human's existence is fragile, 
any tiny change of physic parameter in the universe will have a serious impact on human's existence. Therefore, we'd better end the internal conflicts, unite as one, and extend the vision to the universe.

Human should appreciate the universe and our ancestors who left us the wisdom about the universe and philosophy of life. We'd better further learn and explore the universe.

Peace is a slogan. But the knowledge of universe based on modern physics is the thought from cosmology, and might turn into action via further think and perception. Human shares a common destiny, which makes us face the future together.

\section{Conclusion}

The universe is a multidimensional objective existence with energy as its essential form. The form of energy varies according to different dimensions. Intellectual matter is a special form for the universe's existing, including mankind itself. Therefore, exploring the universe, in some degree, means exploring human's future.

When we are looking at the sky, we should know that exploring the universe, to some degree, means exploring the humanity's future.

\section{Conflicts of Interest}

The author declares no conflicts of interest regarding the publication of this paper.

\section{References}

Berman, M. S., \& da Costa, N. C. A. (2012). On the Stability of Our Universe. Journal of Modern Physics, 3, 1211-1215. https://doi.org/10.4236/jmp.2012.329156

Chechin, L. M. (2010). The Cosmic Vacuum and the Rotation of Galaxies. Astronomy Reports, 54, 719-723. https://doi.org/10.1134/S1063772910080044

Chechin, L. M. (2012). The Dynamics of Cosmic Strings in the Large Metagalaxy. In: J. R. O. Connell, \& A. L. Hale (Eds.), The Big-Bang-Theory, Assumptions and Problems (pp. 103-171). New York: Nova Science Publishers.

Chi, H. H. (1985). What Is Buddhism? Theory and Practice (English Translation by Wei, P.H., Complimentary Dharma Series No. 13, pp. 1-30). Hong Kong: Hong Kong Buddhist Books Distributor.

Godlowski, W. (2011). Local and Global Stability of the Universe. International Journal of Modern Physics D, 703, 354-358.

Jiang, J. S. (2001). Cai Gen Tan: My Crude Philosophy of Life. Changsha: Hunan People's Press (Chinese-English Bilingual Edition).

Laotse (2012). The Wisdom of Laotse (Trans. Lin, Y.). Science and Technology Press.

Le Guin, K. U. (1968). A Wizard of Earthsea. New York: Bantam Books.

Le Guin, K. U. (1970). The Tombs of Atuan. New York: Bantam.

Le Guin, K. U. (1990). Tehanu: The Last Book of Earthsea. New York: Bantam Books.

Le Guin, K. U. (1998). Lao Tzu Tao Te Ching-A Book about the Way and the Power of the Way. Boulder, Colorado: Shambhala Publication. 
Liu, S. (2017). Revelation and Reflection on Mankind by Modern Physics-Part I. Open Journal of Philosophy, 7, 435-447. https://doi.org/10.4236/ojpp.2017.74023

Ni, W.-T. (2008). From Equivalence Principles to Cosmology: Cosmic Polarization Rotation, CMB Observation, Neutrino Number Asymmetry, Lorentz Invariance and CPT. Progress of Theoretical Physics, Supplement, 172, 49-60. https://doi.org/10.1143/PTPS.172.49

Peterson, B. (2016). The Feminine and the Tao: An Interview with Ursula K. LeGuin. Embrace the Moon School for Taijiquan and Qigong.

Rahula, W. (1974). What the Buddha Taught (pp. 16-53). New York: Grove Press.

Sebastian, A. (2014). Structure of Relatively Accelerating Universe. International Journal of Astronomy and Astrophysics, 4, 165-177. https://doi.org/10.4236/ijaa.2014.41015

Su, S. C., \& Chu, M. C. (2009) Is the Universe Rotating? The Astrophysical Journal, 703, 354. https://doi.org/10.1088/0004-637X/703/1/354 